Article

\title{
Rapid Suzuki-Miyaura Couplings with ppm Level of Palladium Catalyst in a High-Pressure and High-Temperature Water System
}

\author{
Ikuhiro Nagao, Maya Chatterjee and Hajime Kawanami * \\ National Institute of Advanced Industrial Science and Technology, 4-2-1 Nigatake, Miyagino-ku, Sendai, \\ Miyagi 983-8551, Japan; inagao2018@gmail.com (I.N.); c-maya@aist.go.jp (M.C.) \\ * Correspondence: h-kawanami@aist.go.jp; Tel.: +81-22-237-2097
}

Received: 21 September 2018; Accepted: 9 October 2018; Published: 12 October 2018

\begin{abstract}
A microflow process was developed for Suzuki-Miyaura Couplings (SMCs) in high-pressure and high-temperature (HPHT) water with a small amount of ethanol. Using this approach, an efficient SMC between 4-methylphenylboronic acid and iodobenzene as a model reaction was demonstrated in water medium, in the presence of ppm order $\mathrm{PdCl}_{2} / \mathrm{NaOH}$ as a simple catalyst/base without any additional ligands, affording the desired products in good yields within $<25 \mathrm{~s}$ of residence time. The strategy developed for SMCs also demonstrated an aspect of separation by quantitative tracing of $0.1 \mathrm{ppm}$ contaminated Pd with the product, which might be attributed to the low catalyst amount along with the reaction conditions, as well as the immediate membrane separation applied in the sequence.
\end{abstract}

Keywords: high-pressure and high-temperature water; Suzuki-Miyaura Couplings; microflow; palladium; continuous separation

\section{Introduction}

Increasing concerns about the development of sustainable chemical technologies, mean there have been huge demands for processes which combine high production efficiency with low environmental burden, process safety, and economic viability. From this perspective, utilization of water as a reaction medium would be one of the most attractive solutions for a chemical process [1-7]. Water is highly abundant, chemically stable, non-toxic, cost-effective and safe compared with most volatile organic solvents used in traditional chemical synthesis. High-pressure and high-temperature (HPHT) water, which includes sub- and supercritical states, exhibits a variety of unique physical properties, such as low polarity, increased ionic constants, and high diffusion coefficients etc., not observed in non-HPHT water [8-11]. As a result, HPHT water possesses the potential to act as a better solvent to catalysts and substrates than conventional water, and also to provide an accelerated reaction rate because of the high boiling temperature, over $100{ }^{\circ} \mathrm{C}$ of water, under atmospheric pressure conditions [12-17]. In addition, the significant differences in physical properties between conventional water and HPHT water might offer some opportunities to reduce the number of reaction steps related to workup and/or purification procedures, and thus be energy efficient.

The continuous sequential flow process represents one of the modern chemical synthesis technologies [18-24]. The most significant part of this approach is the capability to conduct a multi-step process sequentially or automatically. An individual synthesis involves not only the delivery of reagents, but a combination of a number of sequences such as reaction/quenching, extraction/separation/purification of products and analysis. Using a continuous sequential flow process, and efficient mixing, together with heat and mass transfer within micro-channels, allows us to 
control process conditions precisely, thus providing the secured homogeneity and/or reproducibility of the process. In addition, this strategy is inherently flexible; simply by adjusting the number of steps it is possible to scale-up the process with reduced time.

Nowadays, sequential flow process techniques are one of the major options for HPHT water mediated organic reactions because of the outstanding heat transfer characteristics [25,26]. The technological merger between flow sequential process and HPHT water provides promising opportunities to conduct different types of reactions to obtain products with good yields and selectivities [27-29]. Considering the practical aspects of the developed system should be of particular importance concerning the overall process sequence with respective module technologies.

Scheme 1 shows a model representation of Suzuki-Miyaura couplings (SMCs) between organoboron and organic halide substrates, catalyzed by homogeneous Palladium complexes and a base, for production of the corresponding cross-coupling compounds [30]. SMCs have already been found not only in the academic area [31] but also in diverse industrial applications such as in agrochemicals [32], pharmaceuticals [33], functional materials [34], and several kinds of intermediates [35-38]. The process involves various intrinsic characteristics; thus, reaction parameters are critical and highly relevant for extending the practical applicability; for instance: (1) optimum reagent compositions; the amount of substrates, equivalent base and amounts of catalysts, whose variation could directly affect material costs of procurement; (2) formation of undesired homo-coupled by-products, and residual of the catalyst and base after reaction completion, along with the desired cross-coupled compound, is problematic in terms of separation and purification to achieve a higher grade of purity; (3) the co-existence of both organics and inorganics during processing, which might cause solidification and thus clogging in the flow channels because of the huge difference in their polarity [37].

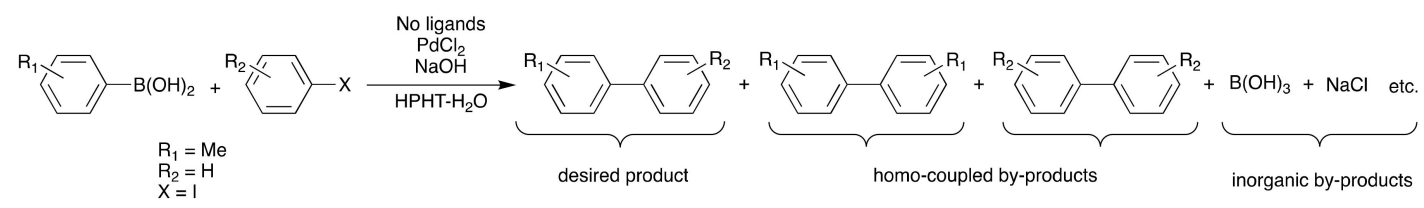

Scheme 1. Suzuki-Miyaura Couplings (SMCs) in high-pressure and high-temperature (HPHT) water in microreactor.

Herein, we report that SMCs (Scheme 2) in HPHT water catalyzed by ppm level of simple $\mathrm{PdCl}_{2}$ with a small amount of ethanol was successfully achieved using the flow sequential process. The developed system also demonstrated sequential separation by using the membrane separator immediately. The developed processes have the potential to perform these coupling reactions with high efficiency to obtain good yields of products.

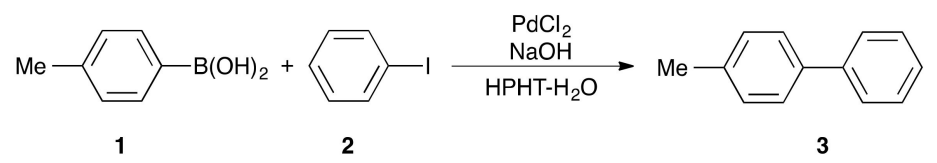

Scheme 2. SMC with 4-methylphenylboronic acid (1) and iodobenezene (2) as a model reaction in HPHT water.

\section{Results and Discussion}

Configurations of a flow sequential process are presented in Figure 1 and details are shown in the Supplementary information. The general experimental procedures are as follows: two liquid pumps were connected for feeding of an aqueous solution and an ethanol solution of substrates. $\mathrm{PdCl}_{2}(1.0 \mathrm{mM})$ with $\mathrm{NaOH}(1.0 \mathrm{M})$ was chosen as a set of catalyst with base system on the basis of the vast literature reported for the reaction in water. $\mathrm{H}_{2} \mathrm{O}$ and aqueous solution of $\mathrm{PdCl}_{2}$ with $\mathrm{NaOH}$ were introduced through pump 1 (at $4.24 \mathrm{~mL} / \mathrm{min}$ ) and pump 2 (at $0.4 \mathrm{~mL} / \mathrm{min}$ ) with the flow rate 
of $4.64 \mathrm{~mL} / \mathrm{min}$, respectively, and heated up to HPHT water conditions using heater 1 in advance, prior to reaction. 4-methylphenylboronic acid $(0.5 \mathrm{M})$ and iodobenzene $(0.5 \mathrm{M})$, as model substrates, and $\mathrm{EtOH}$ as co-solvent were fed by pump 3 at the flow rate of $0.16 \mathrm{~mL} / \mathrm{min}$ followed by mixing in a micromixer. The solution then underwent HPHT reaction conditions by passing through tube reactor (od: $1.58 \mathrm{~mm}$, id: $0.5 \mathrm{~mm}$ ) attached with heater 2 . After the reaction, the solution was cooled down by mixing $\mathrm{n}$-hexane in the heat exchanger, followed by depressurization with a back-pressure regulator. The obtained 2-phase solution was separated by passing through the membrane separator into the hexane phase (bottle 6) and aqueous phase (bottle 5, Figure 1a). All of the experimental details are summarized in Table S1.
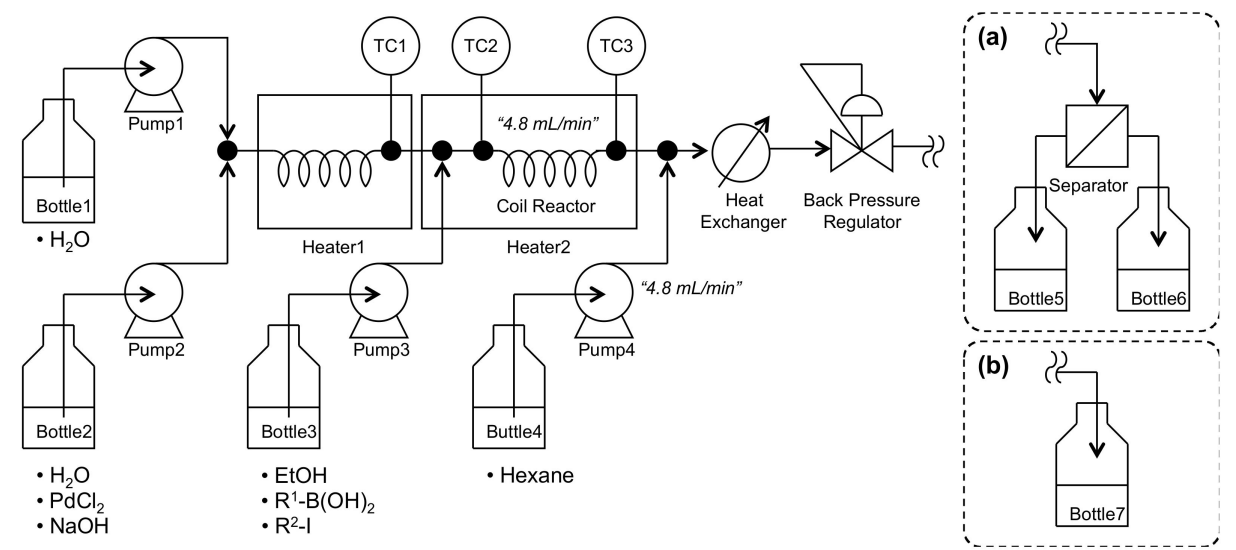

Figure 1. Schematic process configurations of sequential flow reaction for Suzuki-Miyaura Couplings (SMCs). (a) Separation by membrane separator into h-hexane phase and aqueous phase, (b) without separation.

In order to achieve satisfactory yields of a cross-coupled product, the reaction was performed with variations of reaction parameters and the results are shown in Table 1. At first, 4-methylphenylboronic acid (1), iodobenezene (2), $\mathrm{PdCl}_{2}\left(5.0 \times 10^{-1} \mathrm{~mol} \%\right)$ and $\mathrm{NaOH}$ (5.0 eq.) were subjected to the reaction conditions of $50{ }^{\circ} \mathrm{C}$ and $16 \mathrm{MPa}$ with residence time of $24.4 \mathrm{~s}$, affording the desired product 4-methylbiphenyl (3) in 38\% yields (entry 1). Then, maintaining a constant pressure of $16 \mathrm{MPa}$, the reaction temperature was increased to $200{ }^{\circ} \mathrm{C}$, and the yield of 3 was improved to $98 \%$ (entries 2 to 5). As shown in Figure 2 (and Table S2), the yield decreased over $200{ }^{\circ} \mathrm{C}$, which is mainly due to the decomposition of iodobenzene 2. At the fixed reaction temperature of $200{ }^{\circ} \mathrm{C}$, reducing the concentrations of $\mathrm{PdCl}_{2}$ and $\mathrm{NaOH}$ to $2.5 \times 10^{-1} \mathrm{~mol} \%$ and $250 \mathrm{~mol} \%$, respectively, had negligible effects on the yield of 3 (entries 6 , and 7). It has to be mentioned that no clogging was observed in the flow channel in the current process, which proved the versatility of the studied process and its applicability for either organic or inorganic compounds in SMCs.

Table 1. SMC in HPHT water ${ }^{1}$.

\begin{tabular}{cccccc}
\hline Entry & Temp. $\left({ }^{\circ} \mathbf{C}\right)$ & $\left.\mathbf{P d C l}_{\mathbf{2}} \mathbf{( \mathbf { m o l }} \mathbf{\%}\right)$ & $\mathbf{N a O H}(\mathbf{m o l} \mathbf{\%})$ & Time $\mathbf{( s )}$ & Yield of $\mathbf{3} \mathbf{~ \% )}$ \\
\hline 1 & 50 & $5.0 \times 10^{-1}$ & 500 & 24.4 & 38 \\
2 & 100 & $5.0 \times 10^{-1}$ & 500 & 23.7 & 75 \\
3 & 125 & $5.0 \times 10^{-1}$ & 500 & 23.2 & 82 \\
4 & 175 & $5.0 \times 10^{-1}$ & 500 & 22.1 & 83 \\
5 & 200 & $5.0 \times 10^{-1}$ & 500 & 21.5 & 98 \\
6 & 200 & $2.5 \times 10^{-1}$ & 500 & 21.5 & 98 \\
7 & 200 & $2.5 \times 10^{-1}$ & 250 & 21.5 & 96 \\
8 & 200 & $1.25 \times 10^{-1}$ & 250 & 21.5 & 97 \\
9 & 200 & $2.5 \times 10^{-2}$ & 250 & 21.5 & 98 \\
10 & 200 & $2.5 \times 10^{-3}$ & 250 & 21.5 & 99 \\
\hline
\end{tabular}

${ }^{1}$ Reactor volume in heater 2 (in Figure 1): $1.96 \mathrm{~mL}$ (od: $1.58 \mathrm{~mm}$, id: $0.5 \mathrm{~mm}, 1=10 \mathrm{~m}$ ). Gas Chromatograph (Agilent $6890 \mathrm{~N}$ ) and ${ }^{1} \mathrm{H}-\mathrm{NMR}$ (Bruker Avance 400) data of the products are shown in Figures S2 and S3. 
Then we tested the reagents' composition in order to manifest the beneficial aspects obtained from our HPHT water approach. According to the literature, extremely low loading of palladium catalyst (only ppm or ppb orders) could efficiently mediate SMCs depending on the reaction conditions. For example, Handa et al., achieved efficient SMCs with ppm order of palladium catalyst in aqueous solutions [39]. We gradually reduced the loading amount of $\mathrm{PdCl}_{2}$, while keeping the amount of $\mathrm{NaOH}$ constant at $250 \mathrm{~mol} \%$ (entries 8 to 10 , Table 1). It was found that $2.5 \times 10^{-3} \mathrm{~mol} \%(25 \mathrm{ppb}$ ) of the catalyst can effectively produce 3 with an almost quantitative yield in HPHT water. While the catalyst amount could potentially be reduced further to ppb levels, the range applied was maintained within technically controllable concentrations.

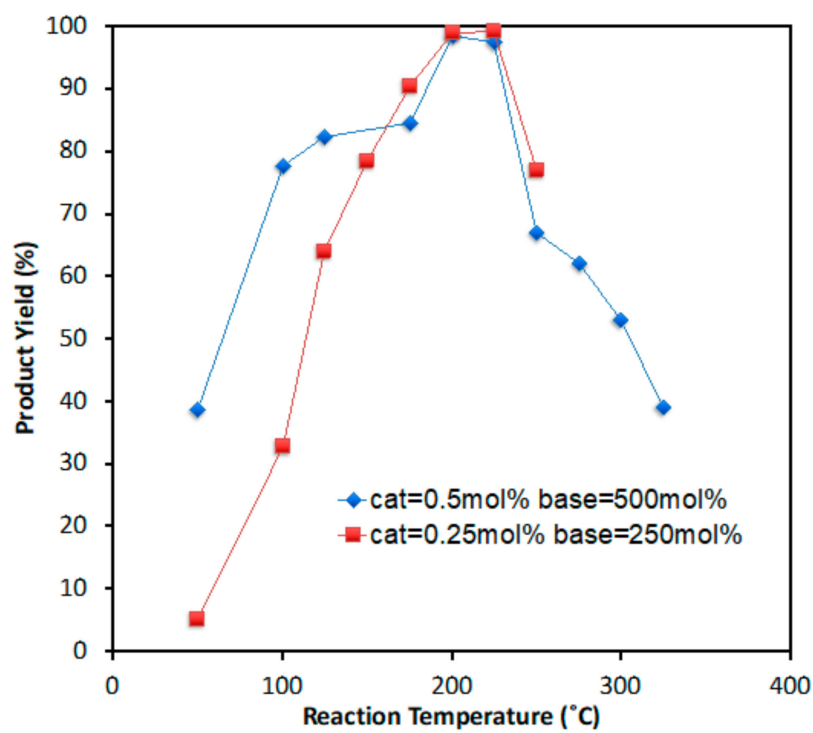

Figure 2. The effect of the reaction temperature for yield of 3 by SMC in HPHT water at the different concentrations of catalyst; $\$ .5 \mathrm{~mol} \%$ of $\mathrm{PdCl}_{2}, 500 \mathrm{~mol} \%$ of $\mathrm{NaOH}, \mathbf{\square}: 0.25 \mathrm{~mol} \%$ of $\mathrm{PdCl}_{2}$, $250 \mathrm{~mol} \%$ of $\mathrm{NaOH}$.

We also continued the reaction with a decreased amount of $\mathrm{NaOH}$. The obtained results under the conditions at temperatures of $200{ }^{\circ} \mathrm{C}$ and $225^{\circ} \mathrm{C}$ in the residence time of $20 \mathrm{~s}$ are presented in Figure 3 . Results show that the yield of 3 maintained its constancy until $150 \mathrm{~mol} \%$ but started to decrease as the amount changed to less than $100 \mathrm{~mol} \%$, and followed a linear trend with the reduced equivalence. It should be noted that if $110 \mathrm{~mol} \%$ of $\mathrm{NaOH}$ was loaded, the reaction could achieve a very good yield at $90 \%$. This observation is very intriguing, considering that most reported SMCs have generally required three to four equivalences of bases. The successful reduction of the amount of $\mathrm{PdCl}_{2}$ as well as $\mathrm{NaOH}$ to a minimum could be the result of proper reaction conditions accomplished by the HPHT water flow approach. Furthermore, the accelerated reaction rate can be confirmed from the shortened residence time of $21 \mathrm{~s}$, compared with the literature, and should be attributed to higher reactivity of 2 as aryliodide. It has been reported that several minutes of residence time were required for SMCs of arylbromides ( 7 min; catalyst: $8.0 \times 10^{-3} \mathrm{~mol} \%$ ) and arylchloride (16 min; catalyst: $2.5 \times 10^{-1} \mathrm{~mol} \%$ ). Here we provide a concise and precise description of the experimental results and their interpretation, as well as the experimental conclusions that can be drawn.

We evaluated the catalytic efficiency to confirm the limits on residence time for the reaction of 2 by varying reactor volumes. Figure 4 shows the results of product yields depending on the residence time at selected temperatures. At $175-225^{\circ} \mathrm{C}$, the residence time was shortened $10 \mathrm{~s}$, and afforded the product in almost quantitative yields. Only $2 \mathrm{~s}$ of residence time was sufficient enough to obtain the yield of $90 \%$ at $225^{\circ} \mathrm{C}$. The corresponding turnover frequencies (TOFs) of the Pd catalyst revealed a maximum TOF of $4.0 \times 10^{4} \mathrm{~s}^{-1}$ (Figure S4) had been reached as the initial rate, considering that high-diluted conditions $(0.016 \mathrm{M})$ were applied as the initial concentration of substrates for the process. 
Naturally, the value of TOFs decreased as the reaction progressed, since the concentration of substrates decreased. However, the averaged TOFs were maintained sufficiently high as $4.0 \times 10^{3} \mathrm{~s}^{-1}$ at the temperature of 175 to $225^{\circ} \mathrm{C}$.

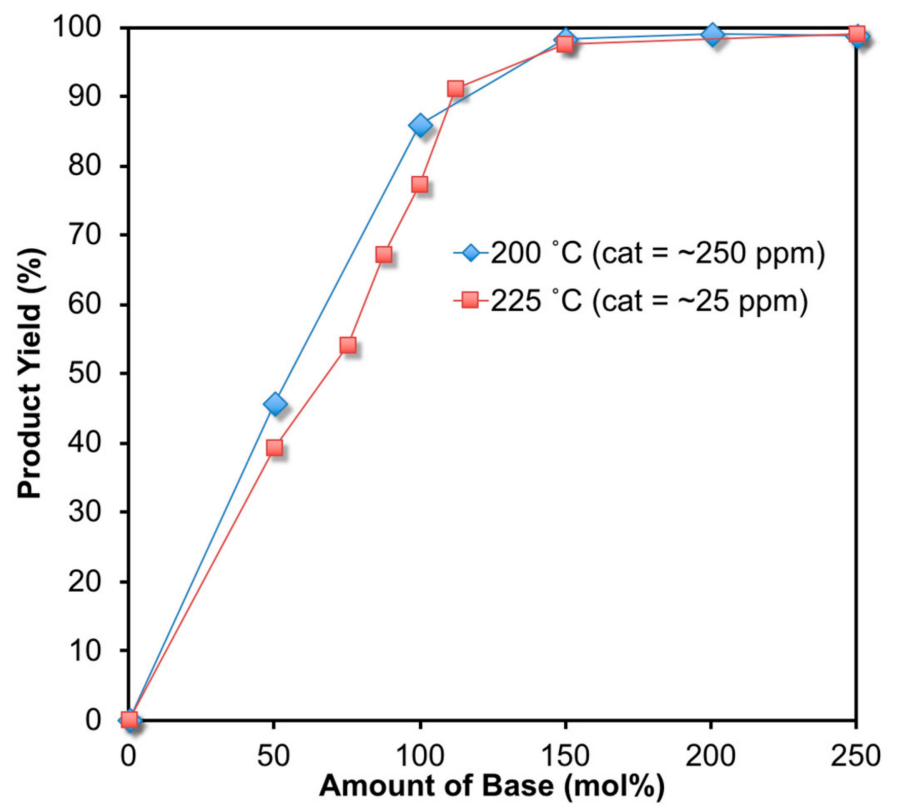

Figure 3. The effect of amount of base on yields of 3 in SMCs; : the yield of 3 at $225{ }^{\circ} \mathrm{C}$ with $0.025 \mathrm{~mol} \%$ of $\mathrm{PdCl}_{2}$, the yield of 3 at $200{ }^{\circ} \mathrm{C}$ with $0.25 \mathrm{~mol} \%$ of $\mathrm{PdCl}_{2}$.

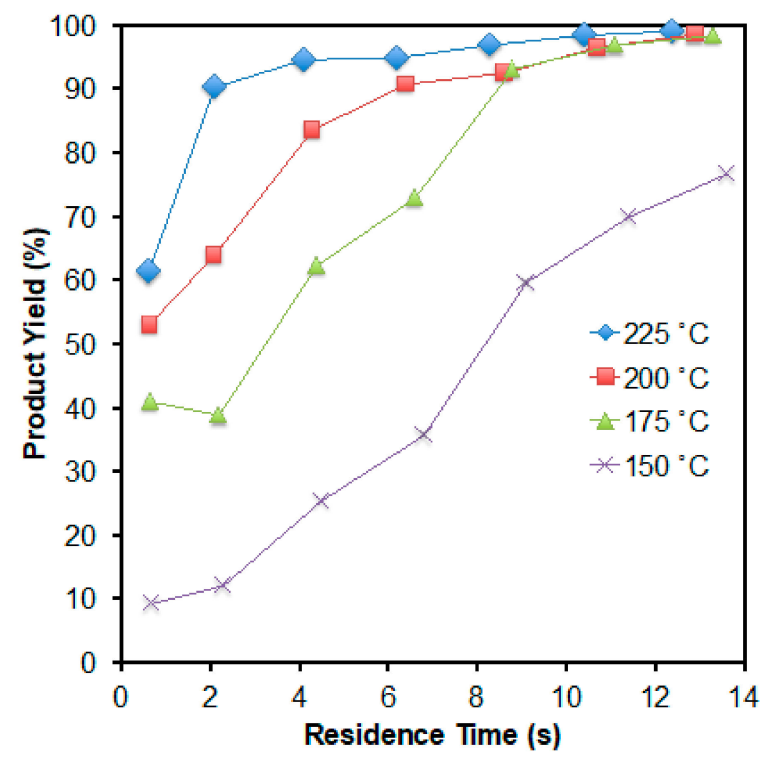

Figure 4. The residence time effect for the yield of 3 in SMC; $225^{\circ} \mathrm{C}, \boldsymbol{\square}: 200^{\circ} \mathrm{C}, \mathbf{\Delta}: 175^{\circ} \mathrm{C}, \times: 150^{\circ} \mathrm{C}$.

We also evaluated the yield of by-products by varying the concentration of each of the substrates (1 and 2) under the optimized condition obtained before (Table S4 and Figure S5 in supplementary information). Small amounts of 4,4'-dimethyl-1,1'-biphenyl 4 and $1,1^{\prime}$-biphenyl 5 were detected as by-products derived by the homocoupling of $\mathbf{1}$ and $\mathbf{2}$. Fortunately, the yield of $\mathbf{3}$ was maintained over $96 \%$, whereas the yield of 4 was increased with increasing concentrations of substrate. By-product formation from homo-couplings is a well-known phenomenon in SMCs and is related to less solubility of substrates in HPHT water. Even though the properties of HPHT water changed to 
a hydrophobic fluid under HPHT conditions, hydrocarbons still have limited solubility in HPHT water. Thus, the by-production occurred with the insoluble substrate.

In our system, we also attached a sequential membrane separator $[40,41]$ to remove $\mathrm{Pd}$ salt from the products for the continuous production of desired products by SMCs (Figure 5, Table 2). The 2-phase reaction solution with a hexane phase and aqueous phase can be separated automatically into aqueous and organic phases. The amount of Pd in each phase was analyzed by ICP (SII Plasma Spectrometer SPS7800). After removing the solvent from the organic phase, a low concentration of contaminated $\mathrm{Pd}\left(7.4 \times 10^{-6}\right.$ wt \%; less than $0.1 \mathrm{ppm}$ of $\left.\mathrm{Pd}\right)$ was detected in the product. On the other hand, in the aqueous solution, Pd was dissolved with the concentration of $>20 \mathrm{mg} / \mathrm{L}$, and $>44 \%$ of Pd could be recovered. The rest of the Pd might be immobilized on the membrane as Pd black nano-particles. In the case of conventional batch-wise operation, $6.1 \times 10^{-5} \mathrm{wt} \% \mathrm{Pd}$ remained in the product, and over $20 \mathrm{mg} / \mathrm{L}$ of $\mathrm{Pd}$ was found to dissolve in the aqueous phase because of the separation problem. This result confirmed that the amount of Pd that remained in the products was higher than in the case of membrane separation, and further purification is necessary. Thus, the continuous membrane separation must be effective to avoid the separation and purification of the product from the metal contaminant.

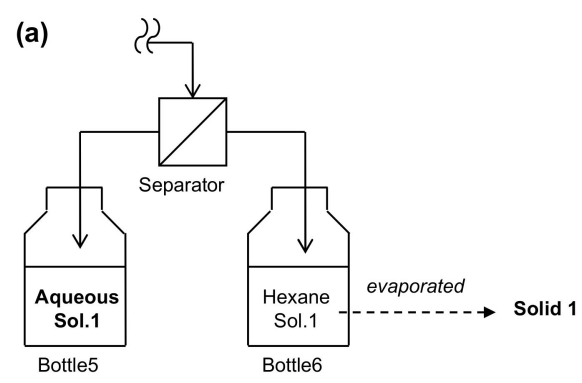

(b)

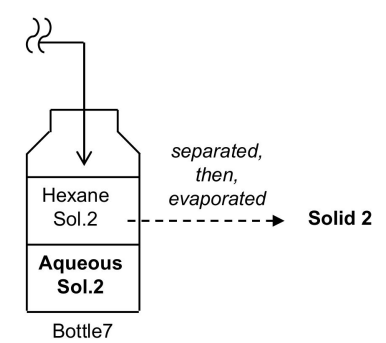

Figure 5. Schematic diagram of (a) membrane separation of reaction solution into organic phase and aqueous phase and $(\mathbf{b})$ without separator.

Table 2. Membrane separation of the reaction solution ${ }^{1}$.

\begin{tabular}{|c|c|c|c|c|c|}
\hline \multirow{2}{*}{ Entry } & \multirow{2}{*}{ Separator } & \multirow{2}{*}{ Sample } & \multicolumn{3}{|c|}{ Pd Content } \\
\hline & & & Conc. & Molar Ratio & Pd Yield \\
\hline 1 & \multirow{2}{*}{ Membrane } & Solid 1 & $7.4 \times 10^{-6}$ wt $\%$ & $1.2 \times 10^{-5} \mathrm{~mol} \%$ & $0.47 \%$ \\
\hline 2 & & Aq. Sol. 1 & $>20 \mathrm{mg} / \mathrm{L}$ & - & $<44 \%$ \\
\hline 3 & \multirow{2}{*}{ Non } & & $6.1 \times 10^{-5} \mathrm{wt} \%$ & $9.6 \times 10^{-5} \mathrm{~mol} \%$ & $3.9 \%$ \\
\hline 4 & & data & $>20 \mathrm{mg} / \mathrm{L}$ & - & $<44 \%$ \\
\hline
\end{tabular}

${ }^{1}$ Reaction conditions: 1 (1 eq.), 2 (1 eq.), $\mathrm{PdCl}_{2}\left(2.5 \times 10^{-5} \mathrm{~mol} \%\right), \mathrm{NaOH}$ (2.5 eq.), $200{ }^{\circ} \mathrm{C}, 16 \mathrm{MPa}$.

\section{Materials and Methods}

For all the experiments, total flow rates of water and substrates solution from liquid pumps were kept constant at $4.8 \mathrm{~mL} / \mathrm{min}$ under ambient conditions. All chemicals were purchased from Wako Pure Chemical Cooperation (Tokyo, Japan), Tokyo Chemical Industry Co., Ltd. (Tokyo, Japan), and Sigma-Aldrich Co. LLC (St. Louis, MI, USA). All the reaction conditions and results are shown in Table S1 in the supplementary information.

\section{Conclusions}

In conclusion, we report a SMC between 4-methylphenylboronic acid and iodobenzene as a model reaction in HPHT water, with small amount of ethanol as a co-solvent for substrates to flow, using ppm level of a simple $\mathrm{Pd}$ salt and $\mathrm{NaOH}$ in a flow sequential process. Without any additives, the developed processes have the potential to produce desired products with good yields. Although we have a 
concern that the process has a limitation regarding the issues of the physical properties of HPHT water for SMCs concerning realistic benefits, the current process still proved its efficiency with a small amount of the catalyst (ppm order). The developed strategy of SMCs also demonstrated an aspect of separation by quantitative tracing of $0.1 \mathrm{ppm}$ contaminated Pd with the product, which might be attributed to the low catalyst amount along with the reaction conditions, as well as the immediate membrane separation applied in the sequence.

Supplementary Materials: The following are available online at http:/ / www.mdpi.com/2073-4344/8/10/451/s1, Figure S1, Figure S2, Figure S3, Figure S4, Figure S5, Figure S6, Table S1, Table S2, Table S3, Table S4.

Author Contributions: Conceptualization, methodology, supervision and project administration, H.K.; experiment, investigation, data curation, resources, visualization, writing-original draft preparation and writing-review and editing, and funding acquisition, H.K., I.N. and M.C.

Funding: This research was partly supported by a Grant-in-Aid for Research Activity start-up (JSPS KAKENHI Grant Number 15H06892).

Acknowledgments: We thank Takayuki Ishizaka in AIST for his support with apparatus for the high-pressure and high-temperature experiments.

Conflicts of Interest: The authors declare no conflicts of interest.

\section{References}

1. Lipshutz, B.H.; Ghorai, S.; Cortes-Clerget, M. The Hydrophobic Effect Applied to Organic Synthesis: Recent Synthetic Chemistry "in Water". Chem. Eur. J. 2018, 24, 6672-6695. [CrossRef] [PubMed]

2. Lipshutz, B.H.; Gallou, F.; Handa, S. Evolution of Solvents in Organic Chemistry. ACS Sustain. Chem. Eng. 2016, 4, 5838-5849. [CrossRef]

3. Saikia, B.; Boruah, P.R.; Ali, A.A.; Sarma, D. 'On-water' organic synthesis: A green, highly efficient, low cost and reusable catalyst system for biaryl synthesis under aerobic conditions at room temperature. RSC Adv. 2015, 5, 50655-50659. [CrossRef]

4. Kitanosono, T.; Masuda, K.; Xu, P.; Kobayashi, S. Catalytic Organic Reactions in Water toward Sustainable Society. Chem. Rev. 2018, 118, 679-746. [CrossRef] [PubMed]

5. Chatterjee, A.; Ward, T.R. Recent Advances in the Palladium Catalyzed Suzuki-Miyaura Cross-Coupling Reaction in Water. Catal. Lett. 2016, 146, 820-840. [CrossRef]

6. Hailes, C.H. Reaction Solvent Selection: The Potential of Water as a Solvent for Organic Transformations. Org. Process Res. Dev. 2007, 11, 114-120. [CrossRef]

7. Rao, K.U.; Appa, R.M.; Lakshmidevi, J.; Vijitha, R.; Rao, K.S.V.K.; Narasimhulu, M.; Venkateswarlu, K. $\mathrm{C}(\mathrm{sp} 2)-\mathrm{C}(\mathrm{sp} 2)$ Coupling in Water: Palladium (II) Complexes of N-Pincer Tetradentate Porphyrins as Effective Catalyst. Asian J. Chem. 2017, 6, 751-757. [CrossRef]

8. Weingartner, H.; Franck, E.U. Supercritical water as a solvent. Angew. Chem. Int. Ed. 2005, 44, 2672-2692. [CrossRef] [PubMed]

9. Savage, P.E. Organic Chemical Reactions in Supercritical Water. Chem. Rev. 1999, 99, 603-622. [CrossRef] [PubMed]

10. Kaul, D.B.; Kaul, C.; Krämer, A.; Krammer, P.; Richter, T.; Jung, M.; Vogel, H.; Zehner, P. Chemistry in Supercritical Water. Angew. Chem. Int. Ed. 1999, 38, 2998-3014.

11. Marcus, Y. Supercritical Water, a Green Solvent: Properties and Uses; John Wiley \& Sons, Inc.: Hoboken, NJ, USA, 2012; ISBN 1118310276.

12. Akizuki, M.; Fujii, T.; Hayashi, R.; Oshima, Y. Effects of water on reactions for waste treatment, organic synthesis, and bio-refinery in sub- and supercritical water. J. Biosci. Bioeng. 2014, 117, 10-18. [CrossRef] [PubMed]

13. Kruse, A.; Dinjus, E. Hot compressed water as reaction medium and reactant Properties and synthesis reactions. J. Supercrit. Fluids 2007, 39, 362-380. [CrossRef]

14. Akiya, N.; Savage, P.E. Roles of Water for Chemical Reactions in High-Temperature Water. Chem. Rev. 2002, 102, 2725-2750. [CrossRef] [PubMed]

15. Siskin, M.; Katritzky, A.R. Reactions in High-Temperature Aqueous Media. Chem. Rev. 2001, 101, 825-835. [CrossRef] [PubMed] 
16. Kus, N.S. Organic reactions in subcritical and supercritical water. Tetrahedron 2012, 68, 949-958. [CrossRef]

17. Watanabe, M.; Sato, T.; Inomata, H.; Smith, R.L., Jr.; Arai, K.; Kruse, A.; Dinjus, E. Chemical Reactions of C1 Compounds in Near-Critical and Supercritical Water. Chem. Rev. 2004, 104, 5803-5821. [CrossRef] [PubMed]

18. Gutmann, B.; Cantillo, D.; Kappe, C.O. Continuous-flow technology-A tool for the safe manufacturing of active pharmaceutical ingredients. Angew. Chem. Int. Ed. 2015, 54, 6688-6728. [CrossRef] [PubMed]

19. Bennett, J.A.; Kristof, A.J.; Vasudevan, V.; Genzer, J.; Srogl, J.; Abolhasani, M. Microfluidic Synthesis of Leastomeric Microparticles: A Case Study in Catalysis of Palladium-Mediated Cross-Coupling. AIChE J. 2018, 64, 3188-3197. [CrossRef]

20. Hartman, R.L.; McMullen, J.P.; Jensen, K.F. Deciding whether to go with the flow: Evaluating the merits of flow reactors for synthesis. Angew. Chem. Int. Ed. 2011, 50, 7502-7519. [CrossRef] [PubMed]

21. Malet-Sanz, L.; Susanne, F. Continuous flow synthesis. A pharma perspective. J. Med. Chem. 2012, 55, 4062-4098. [CrossRef] [PubMed]

22. Vaccaro, L.; Lanari, D.; Marrocchi, A.; Strappaveccia, G. Flow approaches towards sustainability. Green Chem. 2014, 16, 3680-3704. [CrossRef]

23. Wiles, C.; Watts, P. Continuous flow reactors: A perspective. Green Chem. 2012, 14, 38-54. [CrossRef]

24. Hübner, S.; Steinfeldt, N.; Jähnisch, K. Synthesis of Fine Chemicals. In Microreactors in Preparative Chemistry; Reschetilowski, W., Ed.; Wiley-VCH: Weinheim, Germany, 2013; pp. 115-164.

25. Hessel, V.; Cortese, B.; de Croon, M.H.J.M. Novel process windows-Concept, proposition and evaluation methodology, and intensified superheated processing. Chem. Eng. Sci. 2011, 66, 1426-1448. [CrossRef]

26. Hessel, V.; Kralisch, D.; Kockmann, N.; Noel, T.; Wang, Q. Novel process windows for enabling, accelerating, and uplifting flow chemistry. ChemSusChem 2013, 6, 746-789. [CrossRef] [PubMed]

27. Kawanami, H.; Matsushima, K.; Sato, M.; Ikushima, Y. Rapid and highly selective copper-free sonogashira coupling in high-pressure, high-temperature water in a microfluidic system. Angew. Chem. Int. Ed. 2007, 46, 5129-5132. [CrossRef] [PubMed]

28. Sato, M.; Matsushima, K.; Kawanami, H.; Ikuhsima, Y. A highly selective, high-speed, and hydrolysis-free O-acylation in subcritical water in the absence of a catalyst. Angew. Chem. Int. Ed. 2007, 46, 6284-6288. [CrossRef] [PubMed]

29. Sato, M.; Matsushima, K.; Kawanami, H.; Chatterjee, M.; Yokoyama, T.; Ikuhsima, Y.; Suzuki, T.M. Highly efficient chemoselective $\mathrm{N}$-acylation with water microreaction system in the absence of catalyst. Lab Chip 2009, 9, 2877-2880. [CrossRef] [PubMed]

30. Miyaura, N.; Suzuki, A. Palladium-Catalyzed Cross-Coupling Reactions of Organoboron Compounds. Chem. Rev. 1995, 95, 2457-2483. [CrossRef]

31. Roy, D.; Uozumi, Y. Recent Advances in Palladium-Catalyzed Cross-Coupling Reactions at ppm to ppb Molar Catalyst Loadings. Adv. Synth. Catal. 2018, 360, 602-625. [CrossRef]

32. Rough, A. Fine Chemicals. Chem. Eng. News 2004, 82, 49-67.

33. Wang, H.-L.; Katon, J.; Balan, C.; Bannon, A.W.; Bernard, C.; Doherty, E.M.; Dominguez, C.; Gavva, N.R.; Gore, V.; Ma, V.; et al. Novel Vanilloid Receptor-1 Antagonists: 3. The Identification of a Second-Generation Clinical Candidate with Improved Physicochemical and Pharmacokinetic Propertiesq. J. Med. Chem. 2007, 50, 3528-3539. [CrossRef] [PubMed]

34. Lipshutz, B.H. Applying the Hydrophobic Effect to Transition Metal-Catalyzed Couplings in Water at Room Temperature. In Transition Metal-Catalyzed Couplings in Process Chemistry; Wiley-VCH: Weinheim, Germany, 2013; pp. 299-312. ISBN 9783527332793.

35. Winkle, D.D.; Schaab, K.M. Suzuki Reaction of a Diarylborinic Acid: One-Pot Preparation and Cross-Coupling of Bis(3,5-dimethylphenyl)borinic Acid. Org. Process Res. Dev. 2001, 5, 450-451. [CrossRef]

36. Cole, K.P.; Campbell, M.B.; Forst, M.B.; McClary Groh, J.; Hess, M.; Johnson, M.D.; Miller, R.D.; Mitchell, D.; Polster, C.S.; Reizman, B.J.; et al. An Automated Intermittent Flow Approach to Continuous Suzuki Coupling. Org. Process Res. Dev. 2016, 20, 820-830. [CrossRef]

37. Bullock, K.M.; Mitchell, M.B.; Toczko, J.F. Optimization and Scale-Up of a Suzuki-Miyaura Coupling Reaction: Development of an Efficient Palladium Removal Technique. Org. Process Res. Dev. 2008, 12, 896-899. [CrossRef]

38. Nagao, I.; Ishizaka, T.; Kawanami, H. Rapid production of benzazole derivatives by a high-pressure and high-temperature water microflow chemical process. Green Chem. 2016, 18, 3494-3498. [CrossRef] 
39. Handa, S.; Andersson, M.P.; Gallou, F.; Reilly, J.; Lipshutz, B.H. HandaPhos: A General Ligand Enabling Sustainable ppm Levels of Palladium-Catalyzed Cross-Couplings in Water at Room Temperature. Angew. Chem. Int. Ed. 2016, 55, 4914-4918. [CrossRef] [PubMed]

40. Cervera-Padrell, A.E.; Morthensen, S.T.; Lewandowski, D.J.; Skovby, T.; Kiil, S.; Gernaey, K.V. Continuous Hydrolysis and Liquid-Liquid Phase Separation of an Active Pharmaceutical Ingredient Intermediate Using a Miniscale Hydrophobic Membrane Separator. Org. Process Res. Dev. 2012, 16, 888-900. [CrossRef]

41. Sahoo, H.R.; Kralj, J.G.; Jensen, K.F. Multistep continuous-flow microchemical synthesis involving multiple reactions and separations. Angew. Chem. Int. Ed. 2007, 46, 5704-5708. [CrossRef] [PubMed]

(C) 2018 by the authors. Licensee MDPI, Basel, Switzerland. This article is an open access article distributed under the terms and conditions of the Creative Commons Attribution (CC BY) license (http:// creativecommons.org/licenses/by/4.0/). 